International Journal of Social Science and Economic Research

ISSN: $2455-8834$

Volume: 05, Issue: 03 "March 2020"

\title{
THE NEXUS BETWEEN CHINA CRUDE OIL FUTURES AND SPOTS: A COMPARISON WITH WTI FUTURES
}

\author{
${ }^{* 1}$ Cheng Cheng, ${ }^{1}$ Xingyu Dai \\ ${ }^{1}$ College of Economics and Management, Nanjing University of \\ Aeronautics and Astronautics, Nanjing 211106, China \\ *Corresponding author
}

DOI: 10.46609/IJSSER.2020.v05i03.001 URL: https://doi.org/10.46609/IJSSER.2020.v05i03.001

\begin{abstract}
The aim of this paper is to dig out the nexus between China crude oil futures and eight kinds of crude oil spots around four different aspects, namely mean spillovers, volatility spillovers, dynamic correlation, and dynamic hedging ratio. A comparison is made between the oil futures and spots nexus with WTI futures. Our key findings conclude that WTI futures contributed more spillovers than China crude oil futures. However, China crude oil futures receive more spillovers from the spots than do WTI futures. The dynamic correlation between China crude oil futures and Asian crude oil spots is higher than the correlation of WTI futures. The hedge performance shows that China crude oil futures can be a hedging tool to all Asian oil spots, but this is not the case for spots in Europe and America.
\end{abstract}

Keywords: China crude oil futures; WTI futures; spillover effect; dynamic correlation; oil hedge; copula model

\section{INTRODUCTION}

The role of crude oil futures is mainly to provide information to the spot prices of crude oil, to provide signals for spot price changes, and hedging. China has become the world's largest importer of crude oil and the world's second-largest consumer of crude oil. Medium crude oil is the main type of crude oil imported from China's trade partners and neighboring countries. A future that can represent the information on the medium crude oil market in the Asia-Pacific region is urgently needed. After a long wait, on 26 March 2018, China launched its first-ever crude oil futures in the Shanghai International Energy Exchange (INE). On the opening day, in the afternoon of March 26, the trading volume for the whole day exceeded 40,000 hands. This 


\section{International Journal of Social Science and Economic Research}

ISSN: $2455-8834$

Volume: 05, Issue: 03 "March 2020"

volume was only surpassed by the world's two major crude oil futures trading varieties, WTI futures and Brent futures, ranking China's crude oil third in the world.

The purpose of this paper is to explore the nexus between China crude oil futures and other spot markets. The results could uncover whether or not China crude oil futures fulfilled their expected functions of leading the spot markets and providing information for spots in the past year. However, only a few papers thus far have researched the patterns of China crude oil futures ${ }^{[1]}$. Huang and $\mathrm{Li}^{[2]}$ explore the dynamic correlation between China crude oil futures and OPEC spots, comparing these with WTI and Brent futures. In this paper, we choose eight different representative spot markets worldwide and study the nexus between those spot markets and China oil futures. We compare China oil futures with WTI futures, exploring different nexus features (from different aspects, including returns spillovers, volatility spillovers, dynamic correlation, and dynamic hedging ratio) between China oil futures and WTI futures. The results of this study can clearly answer the question of whether or not China oil futures have fulfilled their expected functions.

Many kinds of research study the nexus between futures and spot markets from the perspective of spillovers, which reflect the information transmitted across markets ${ }^{[3]}$ or the lead-lag relationship ${ }^{[4]}$. Most of these studies use a VAR or VECM-based Granger causality test to discover the returns spillovers among assets ${ }^{[5]}$. Multivariate GARCH models are also used to describe the spillovers in volatility ${ }^{[6]}$. Both the returns spillovers and volatility spillovers present the direction of information spillovers between spots and futures, which can be detected by judging the significance of the coefficient in models. Diebold and Yilmaz ${ }^{[7]}$ introduce a spillover measure based on forecast error variance decompositions from VARs. The study also joins with Pesaran and Shin ${ }^{[8]}$ to perfect the theory in Diebold and Yilmaz ${ }^{[9]}$. The Diebold and Yilmaz spillover index can express the magnitude of spillovers between the two assets with a specific value, clearly indicating if the spillovers exist and the magnitude and direction of those spillovers. The traditional VAR-based or GARCH-based Granger test cannot express this. The Diebold and Yilmaz spillovers index have been successfully applied in spillover research ${ }^{[10]}$, especially in spillovers between futures and spots. Magkonis and Tsouknidis ${ }^{[11]}$ find the existence of dynamic spillover effects between petroleum-based spot-futures volatilities. Antonakakis ${ }^{[12]}$ estimate dynamic volatility spillovers in the stock index futures market. Other scholars have researched futures and spots using the Diebold and Yilmaz spillovers index, as can be seen in Yarovaya ${ }^{[13]}$, among others.

This study is the first comprehensive empirical investigation that seeks to discover the nexus between China crude oil futures and oil spot prices. We choose eight different, very representative and internationally influential oil spot markets from the Asia-Pacific, Middle East, 


\section{International Journal of Social Science and Economic Research}

ISSN: $2455-8834$

Volume: 05, Issue: 03 "March 2020"

Europe, and America regions. What's more, their oil quality types are also different, and this selection can fully reflect the nexus between Chinese crude oil futures and different spot prices, compared to existing research. What's more, our comparative analysis with WTI futures uncovers the different nexus patterns between China oil futures and internationally dominant oil futures. The results could provide strong policy and investment information for policymakers, market regulators and oil futures participants.

Secondly, our study conducts a thorough investigation of the nexus between oil futures and spot prices from four different aspects. The results vividly reveal the information transition, comovement and dynamic hedging effectiveness. The returns spillovers and volatility spillovers show the information transition, which could indicate whether oil futures have the ability to provide information and lead the global oil spot markets. The dynamic correlation could reflect the degree of co-movement at each moment. Finally, the dynamic hedge ratio reflects how many units of futures can offset one unit of spot returns change. The four different perspectives systematically illustrate the nexus patterns. We use the Diebold and Yilmaz spillovers index to explore the returns spillovers and volatility spillovers between oil futures and spots, thereby revealing the nexus feature in information spillovers. This approach provides a different definition of volatility proxy than that found in Diebold and Yilmaz.

Thirdly, we further explore the dynamic correlation between oil futures and spot markets by trying to discover whether China oil futures co-move with different oil spots at a consistent pace, compared to WTI futures, using a time-varying parameter copula. We calculate the hedging effectiveness in different time horizons by exploring the effect of hedging between China-US crude oil futures and other crude oil spot prices under different investment cycles. Investors' hedging horizons may influence the hedging effectiveness ${ }^{[14]}$. The results could provide strong investment suggestions for hedgers.

The remainder of this paper is organized as follows: Section 2 is the methodology introduction. Section 3 introduces the oil futures and spots selected for this study. Section 4 presents the empirical findings, and Section 5 concludes the paper.

\section{ECONOMETRICS APPROACH}

\subsection{Diebold and Yilmaz (2012) spillover index}

Applying the spillover index proposed by Diebold and Yilmaz (2012), extracted from Pesaran and Shin (1998), the daily returns and conditional volatility filtered by the MS-GARCH model are used to calculate the returns spillovers and volatility spillovers.

In this paper, firstly, we construct an N-variable VAR (p) model as follows: 
$\boldsymbol{B}(L) \boldsymbol{R}_{t}=\boldsymbol{\varepsilon}_{t}(1)$

where $\boldsymbol{B}(L)$ is lag polynomial, and $\boldsymbol{B}(L)=\boldsymbol{I}_{N}-\boldsymbol{\Phi}_{1} L-\cdots-\boldsymbol{\Phi}_{p} L^{p}$ and $\boldsymbol{\varepsilon}_{t} \sim(0, \Sigma)$. This can be rewritten as a $\operatorname{VMA}(\infty)$ form, that is,

$\boldsymbol{R}_{t}=\boldsymbol{C}(L) \boldsymbol{\varepsilon}_{t}$

where $\boldsymbol{C}(L)=\boldsymbol{I}_{N}+\boldsymbol{\Psi}_{1} L+\boldsymbol{\Psi}_{2} L^{2}+\cdots$ and $\boldsymbol{\Psi}_{k}=\boldsymbol{\Phi}_{1} \boldsymbol{\Psi}_{k-1}+\boldsymbol{\Phi}_{2} \boldsymbol{\Psi}_{k-2}+\cdots+\boldsymbol{\Phi}_{p} \boldsymbol{\Psi}_{k-p}\left(\boldsymbol{\Psi}_{0}=\right.$ $\left.\boldsymbol{I}_{N}\right)$. Secondly, we have the generalized $H$-step-ahead error variances shares as defined by Pesaran and Shin (1998), which present the shocks of $r_{i}$ in $\boldsymbol{R}_{t}$, received from the shocks of $r_{j}$ in $\boldsymbol{R}_{t}$, that is,

$\theta_{i j}(H)=\frac{\sigma_{j j}^{-1} \sum_{k=0}^{H-1}\left(e_{i}^{\prime} \boldsymbol{\Psi}_{k} \Sigma e_{j}\right)^{2}}{\sum_{k=0}^{H-1}\left(e_{i}^{\prime} \boldsymbol{\Psi}_{k} \Sigma \boldsymbol{\Psi}_{k}^{\prime} e_{j}\right)}$

where $\sigma_{j j}$ is the standard deviation of the error term for the $j$ th equation of $\boldsymbol{R}_{t}$, and $e_{j}$ is the selection vector. Providing that $\sum_{j=1}^{N} \theta_{i j}(H) \neq 1$, the variance shares can be normalized as follows:

$\tilde{\theta}_{i j}(H)=\frac{\theta_{i j}(H)}{\sum_{j=1}^{N} \theta_{i j}(H)}$

Note that, $\sum_{j=1}^{N} \tilde{\theta}_{i j}(H)=1$, and $\sum_{i, j=1}^{N} \tilde{\theta}_{i j}(H)=N$. Using the normalized variance shares, $\tilde{\theta}_{i j}(H)$ presents the magnitude of spillovers index transmitted from asset $j$ to asset $i$. An accumulation volatility spillover index can be constructed as follows:

$S_{\left\{i^{*}\right\}, j}^{a}(H)=\frac{\sum_{i \in\left\{i^{*}\right\}}^{N} \widetilde{\theta}_{i j}(H)}{\sum_{i, j}^{N} \widetilde{\theta}_{i j}(H)} \cdot 100,\left\{i^{*}\right\}$ is the interest asset

which shows the amount of the gross magnitude of spillovers asset $j$ could transmit to asset $\left\{i^{*}\right\}$, which is of interest. Finally, a net of pairwise spillovers can be defined as:

$S_{i, j}^{p}(H)=\left(\frac{\widetilde{\theta}_{i j}(H)}{\sum_{k, j}^{N} \widetilde{\theta}_{k j}(H)}-\frac{\widetilde{\theta}_{j i}(H)}{\sum_{i, k}^{N} \widetilde{\theta}_{i k}(H)}\right) \cdot 100$

which reflects the difference between the spillovers transmitted from asset $i$ to asset $j$ and the spillovers transmitted from asset $j$ to asset $i$. If $S_{i, j}^{p}(H)$ is positive, the asset $j$ is a net transmitter to asset $i$. In this paper, we specify that $H=10$ and $\mathrm{P}=2$, after a number of attempts.

\subsection{Dynamic parameter t-copula model and hedging ratio}


Patton $(2006,2009)$ proposes a dynamic parameter t-copula model to describe the conditional joint distribution of two finance variables, about which only their conditional marginal distribution is known, that is:

$H_{t}\left(r_{1}, r_{2} \mid I\left(r_{1, t-1}, r_{2, t-1}\right)\right)=C\left(F_{1, t}\left(r_{1} \mid I_{t-1}\right), F_{2, t}\left(r_{2} \mid I_{t-1}\right) \mid I\left(r_{1, t-1}, r_{2, t-1}\right)\right)(7)$

where $F_{i, t}$ is the conditional marginal distribution of $r_{i}$, which can be obtained from the MSGARCH model. Also, $H_{t}$ is the conditional joint distribution, and $\mathrm{C}$ is a t-copula function, which is specified as:

$\mathrm{C}_{t}\left(u, v ; \rho_{t}, v \mid I_{t-1}\right)=\int_{-\infty}^{\mathrm{T}_{v}^{-1}(u)} \int_{-\infty}^{\mathrm{T}_{v}{ }^{-1}(v)} \frac{1}{2 \pi \sqrt{1-\rho_{t^{2}}}}\left(1+\frac{x^{2}-2 \rho_{t} x y+y^{2}}{v\left(1-\rho_{t}{ }^{2}\right)}\right)^{\frac{v+2}{-2}} d x d y$

where $\mathrm{T}_{v}{ }^{-1}(x)$ is the Student's $\mathrm{t}$ inverse cumulative density function with a degree of freedom $v$. Also, $\rho_{t}$ reveals the dynamic correlation between two assets, which evolves as:

$\rho_{t}=\Lambda\left(\omega+\alpha \rho_{t-1}+\beta \frac{1}{10} \sum_{q=1}^{10}\left|u_{t-q}-v_{t-q}\right|\right)$

where $\Lambda(x)=\frac{1-e^{-x}}{1+e^{-x}}$. In this paper, we use maximum likelihood estimation to solve the interest parameter, that is, $\{\omega, \alpha, \beta, v\}$, and the Fisher information matrix is used to calculate the standard error of estimators.

According to Kroner and Sultan (1993), the dynamic optimal hedging ratios $\beta_{t}$ between futures and spot prices calculated by minimizing the portfolio risk at time $t$ is as follows:

$\beta_{t}=\frac{\operatorname{cov}\left(r_{s, t}, r_{f, t}\right)}{D\left(r_{f, t}\right)}=\rho_{s f, t} \sqrt{\frac{D\left(r_{s, t}\right)}{D\left(r_{f, t}\right)}}$

where the dynamic correlation $\rho_{s f, t}$ between futures and spots can be obtained from a t-copula model, and the variance of returns can be calculated by the MS-GARCH model. The hedging performance of $\beta_{t}$ can be expressed by the variance reduction, given the things investors care most about is the variance difference before and after hedging, which is given by:

$V R=1-\frac{D\left(r_{s, t}-\beta_{t} r_{f, t}\right)}{D\left(r_{f, t}\right)}$.

For different k-period hedging horizons, the $V R$ could change and reflect the hedge performance with different investment cycles. Following Hou and $\mathrm{Li}$ (2013), we calculate the variance reduction under different time horizons, that is for 1, 5, 10, 20, and 50day(s). 
International Journal of Social Science and Economic Research

ISSN: $2455-8834$

Volume: 05, Issue: 03 "March 2020"

\section{DATA AND PRETREATMENT}

\subsection{Data source}

The China crude oil futures market was launched on the Shanghai International Energy Exchange on March 26, 2018. The trading code is SC (henceforth, we use F_SC for short). As one of the two major benchmark futures in the global oil market, the US West Texas Intermediate Crude Oil Futures (henceforth, F_WTI), is designed and managed by NYMEX. The CME Group is used in a hedge performance comparison with China crude oil futures. Based on the underlying assets of futures, our analysis selects eight kinds of main oil futures spot markets from China and around the world. For the Chinese region, the included spots are Shengli crude oil (SL, henceforth), in Shandong, China which is one of the most important spot price benchmarks in China and the only delivery oil of all of China's crude oil futures. The East-Asia region includes Tapis Crude Oil (TP, henceforth), in Malaysia, which is the benchmark for most of the light crude oil in Southeast Asia and is also known as the world's high-end oil. Also included is Minas crude oil (MN, henceforth), in Indonesia, upon which most of Asia's medium low-sulfur crude oil is based. The Middle East region includes Dubai crude oil (DB, henceforth), in the United Arab Emirates (OPEC member states), which is the delivery oil of China crude oil futures and the benchmark price of crude oil exported from the Middle East to Asia. Oman crude oil (OM, henceforth) is from non-OPEC member states and is also the delivery oil of F_SC. Further, the European and American region spots include Eastern Siberian Pacific Ocean pipeline mixed crude oil (ESPO, henceforth), in Russia, which is a substitute for a variety of medium to heavy crude oils in the Asia Pacific region. This oil is inexpensive, due to pipeline transportation. Also included is Brent crude oil (BR, henceforth), in Sullom Voe, Shetland Islands, North Sea, and WTI crude oil spots in the U.S. (WTI, henceforth), both of which jockey for position as the number one leader in the crude oil market.

Our analysis is based on the daily closing prices spanning from March 27, 2018 (the issue date of F_SC), to March 12, 2019. This totals 220 days of returns, which are obtained from the wind database (which is the most famous data service provider in China) and the U.S. Energy Information Agency (EIA). All prices, except for F_SC, are dominated as USD per barrel, and their $\log$-returns will be defined as $R_{t}=\ln \left(\frac{P_{t}}{P_{t-1}}\right)$, where $P_{t}$ is the daily closing price at time $t$. In order to eliminate the influence of exchange rate factors and also for the convenience of hedging calculation, we use the Intermediate RMB/U.S. Dollar Exchange Rate to convert the F_SC RMB price into the U.S. dollar price. The corrected log-returns are $R_{t}^{c}=\ln \left(\frac{P_{t}}{P_{t-1}}\right)-\ln \left(\frac{F X_{t}}{F X_{t-1}}\right)$, where $F X_{t}$ is the closing price of the Intermediate RMB/US Dollar Exchange Rate. 
International Journal of Social Science and Economic Research

ISSN: $2455-8834$

Volume: 05, Issue: 03 "March 2020"

\subsection{Description statistics}

The summary statistics for two futures and eight spots are presented in Table 1. Except for spots in the Middle East region, the average returns of eight out of the 10 assets are less than 0, clearly indicating that the decline in daily returns during the sample period is more obvious. S.D. shows that the Shengli, Minas, and Brent returns are more volatile than others are. The skewness coefficient shows that almost all assets are left-biased, except for Brent, which is responding to the result of the mean value. During the sample period of this paper, international oil prices continued to fall after the middle of 2018, and it is this background that caused such statistical characteristics. The J-B tests show that some assets, such as F_WTI, Brent, WTI, Oman and Dubai, reject the null hypothesis that the returns are Gaussian distribution, which uncovers the patterns of "higher peak and fat tail phenomena" in their returns. These assets are highly internationalized, and returns are prone to extreme values. The ADF test suggests that all returns are stationary, which is suitable for using the time series model adopted in this paper. However, the LB-Q test shows that there is no autocorrelation in all sequences, so we change the formula (1) and (4) into non-ARMA structures. The LBQ2 test shows the volatility clustering in squared returns, which shows we should apply a GARCH-type model to describe the marginal distribution of the 10 selected assets.

Table 1: Descriptive statistics

\begin{tabular}{|c|c|c|c|c|c|c|c|c|}
\hline & Mean & S.D. & Skewness & Kurtosis & J-B test & ADF test & LBQ test & LBQ2 test \\
\hline \multicolumn{9}{|l|}{ Futures } \\
\hline F_WTI & -0.065 & 1.985 & -0.966 & 5.286 & $82.073 \mathrm{a}$ & $-5.235 \mathrm{a}$ & 19.018 & $26.798 \mathrm{~b}$ \\
\hline F_SC & -0.013 & 1.648 & -0.245 & 2.969 & 2.203 & $-5.497 \mathrm{a}$ & 8.478 & $25.100 \mathrm{~b}$ \\
\hline \multicolumn{9}{|c|}{ European and American region } \\
\hline $\mathrm{BR}$ & -0.020 & 2.054 & 0.046 & 4.235 & $14.048 \mathrm{a}$ & $-5.259 \mathrm{a}$ & 13.922 & $37.254 \mathrm{a}$ \\
\hline WTI & -0.065 & 1.957 & -0.858 & 4.881 & $59.419 \mathrm{a}$ & $-5.167 \mathrm{a}$ & 16.198 & $24.450 \mathrm{c}$ \\
\hline ESPO & -0.005 & 1.775 & -0.306 & 3.198 & 3.791 & $-4.895 \mathrm{a}$ & 12.107 & $27.413 \mathrm{~b}$ \\
\hline \multicolumn{9}{|c|}{ Middle East region } \\
\hline $\mathrm{OM}$ & 0.008 & 1.910 & -0.476 & 3.341 & $9.369 \mathrm{a}$ & $-4.863 \mathrm{a}$ & 7.879 & $23.376 \mathrm{c}$ \\
\hline DB & 0.009 & 1.821 & -0.404 & 3.378 & $7.293 \mathrm{~b}$ & $-5.063 \mathrm{a}$ & 10.409 & $30.705 \mathrm{a}$ \\
\hline \multicolumn{9}{|c|}{ China and East-Asia region } \\
\hline SL & -0.026 & 2.168 & -0.263 & 3.407 & 4.065 & $-4.943 \mathrm{a}$ & 11.069 & $31.555 \mathrm{a}$ \\
\hline TP & -0.008 & 1.827 & -0.235 & 3.314 & 2.927 & $-5.075 \mathrm{a}$ & 6.503 & 17.075 \\
\hline MN & -0.024 & 2.084 & -0.225 & 3.375 & 3.153 & $-5.084 \mathrm{a}$ & 11.271 & $22.531 \mathrm{c}$ \\
\hline
\end{tabular}

Note: A value greater than 0 indicates that futures are a receiver, otherwise, transmitter. 
International Journal of Social Science and Economic Research

ISSN: $2455-8834$

Volume: 05, Issue: 03 "March 2020"

\section{EMPIRICAL RESULTS AND FINDINGS}

\subsection{Diebold and Yilmaz (2012) spillover effects between crude oil futures and oil}

In this section, we extract the patterns of spillover effects on returns and volatility between futures and spots. Filtered by the Markov-switching model, combined with the Diebold and Yilmaz (2012) spillover effects, the conditional volatility can be obtained here.

Figure 1 vividly depicts the directional spillovers between futures and spots using a Chord Diagram. The first column in Figure 1 shows that, as the spillover transmitter, the F_WTI contributes more total spillover effects to all eight kinds of oil spots than does F_SC, both in terms of returns (108.3:47.5) and volatility (103.0:60.5). This finding reflects the international leading status of WTI futures. For specific oil spots, the situation is the same when all spots receive a greater returns spillover effect from F_WTI than from F_SC. However, with regard to the volatility of spillovers, several pairs show that they receive more volatility spillovers from F_SC than from F_WTI. Examples include ESPO, Dubai, and Tapis. This is not strange, because ESPO, Tapis oil, mainly supplied to China, will naturally receive the impact of F_SC. In addition, Dubai crude oil is the delivery product of F_SC and will, therefore, be affected by its volatility spillovers.

Statistics show that WTI (34.1) is the biggest spots receiver in returns spillovers from two futures, followed by Brent (18.9) and Dubai (18.3). These three are the most important spots worldwide, while Minas (16.4) is the last one. In addition, WTI (35.3) is the biggest spots receiver in terms of volatility spillovers from two futures, followed by Brent (33.8), and Dubai (25.8), with Tapis (9.6) being the last. We have found that, as the world's three major crude oil stocks (WTI, BR, DB), they clearly receive the largest spillovers and volatility spillovers from futures. This means that their pricing is very dependent on the futures market, which in turn provides us an investment risk warning. Some crude oils (TP, MN) in Southeast Asia have no mature futures market to use as a benchmark. They mainly focus on some spot prices, so they are less affected by futures.

With regard to being the receiver of returns spillover effects (as shown in the top-right of Figure 1), however, F_WTI (64.5\%) is shown to even receive a lesser share than F_SC (71.4\%). This indicates that the China futures returns could be affected by other spots, while WTI futures returns could be slightly affected. This can be explained by the fact that the position of China's crude oil futures relative to the leading futures markets is relatively weak. China's returns are easily affected by the spot price, while the F_WTI status is higher and its returns are relatively less affected. Further, the returns spillovers patterns from specific spots vary from assets to assets. For instance, the oil spots in the Asia-Pacific and East-Asia region (such as Shengli, 
Minas, and Dubai) transmit more returns spillovers to F_SC (7.6, 7.5, and 8.4, respectively) than to F_WTI $(2.3,2.4$, and 2.9 , respectively). Conversely, only two international spots, namely WTI and Brent, out of all the others transmit more spillovers to F_WTI (31.0, and 15.9, respectively) than to F_SC (14.2, and 11.5, respectively). This difference indicates that local spots could affect China oil futures more heavily than WTI futures, and international spots could affect WTI futures heavily. Investors should pay more attention to these asymmetric returns spillovers. What's more, WTI (44.2) contributes the most returns spillovers to two futures, followed by Brent (27.4).

The bottom-right of Fig. 1 clearly shows that the F_SC (64.1) receives even slightly fewer volatility spillovers than does F_WTI (64.4) in total from the eight kinds of spots. Meanwhile, WTI and Brent contributed a large amount of volatility spillovers to F_WTI, reflecting the greater spillover effect between international spot and futures markets. As a benchmark for international spot pricing, WTI futures are affected very little by other local spot fluctuations, such as those in Tapis, Minas and so on. In fact, WTI (49.6) gives the biggest total volatility spillovers to two futures, followed by Brent (35.7). Oman gives the smallest amount, only accounting for 2.3, followed by Oman (3.5), which indicates that the crude oil in the Asia-Pacific region has contributed less to volatility spillovers. 

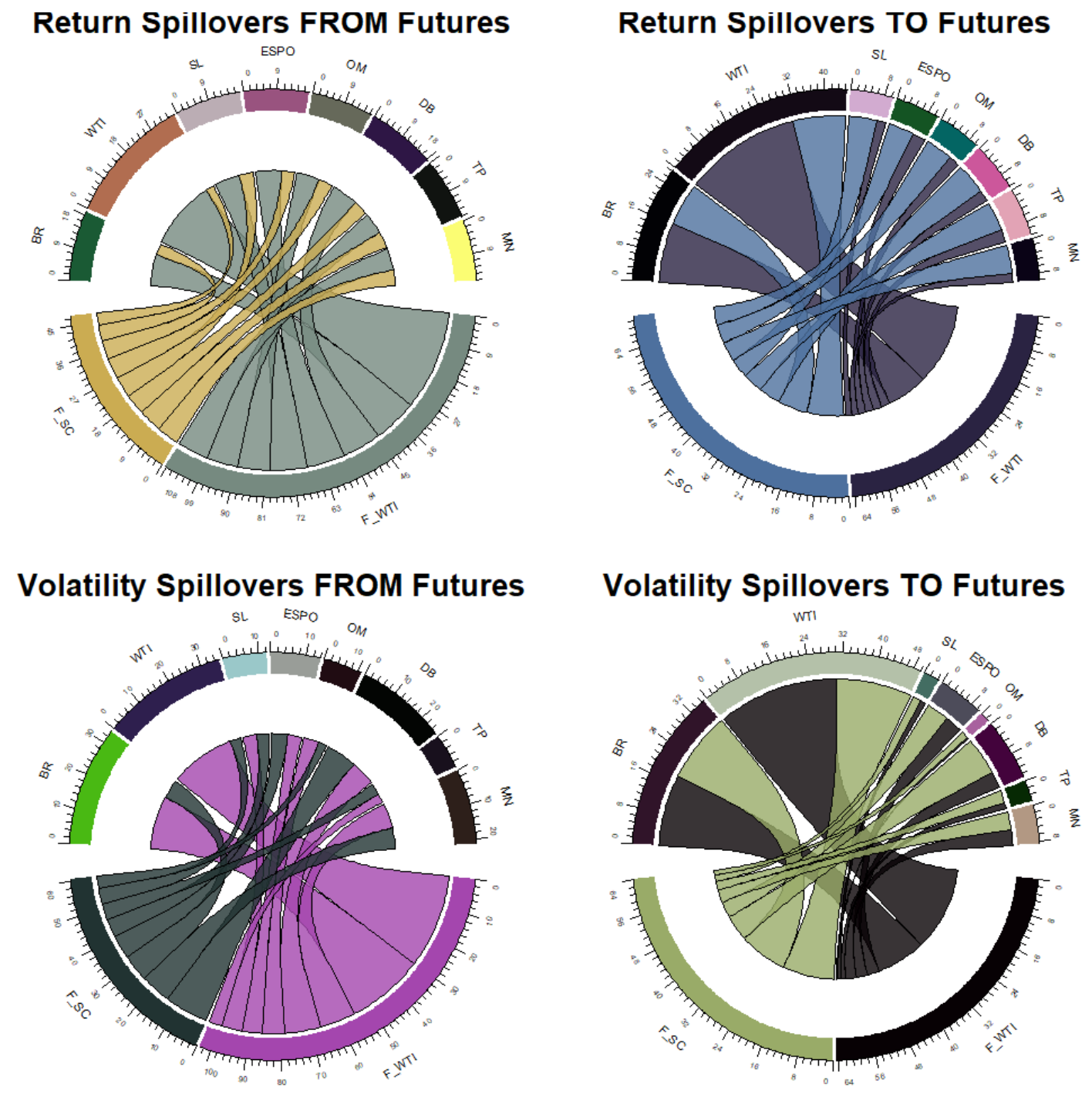

Fig. 1: Directional spillovers between futures and spots

Table 2 shows the ratio of a relative spillover share as summarized from Figure 1. The second column shows that the East-Asia and Middle-East region spots give stronger spillovers to F_SC, while American and European spots contribute stronger spillovers to F_WTI. Particularly, China oil spots (Shengli) give the largest proportion of its returns spillover share to China futures, while America oil spots give the greatest proportion of returns spillover shares to America futures. Crude oil in Asia has a greater impact on Chinese crude oil futures returns. As such, F_SC investors should pay more attention to Asian crude oil spot prices, while F_WTI investors should pay more attention to the spot price of crude oil in Europe and America. 
International Journal of Social Science and Economic Research

ISSN: 2455-8834

Volume: 05, Issue: 03 "March 2020"

The third column shows that F_WTI transmits more returns spillovers to all eight spots than does F_SC. This shows the dominant pricing status of WTI futures, given that all values are less than 1. In terms of proportion, F_SC contributed more returns spillovers to the spot of crude oil in the Asia-Pacific region during the study period. The fourth column shows that the shares spots given to F_SC and F_WTI are different from region to region. Oman and Dubai gave F_SC a relatively large volatility spillover, probably because both Oman and Dubai were the target spot of F_SC. Shengli also contributed a lot. In addition, BR and WTI gave F_WTI a relatively large volatility spillover, for the same reason. Further, those two are also the only spots that give more volatility spillovers to F_WTI than to F_SC. The authors believe that the size of the volatility spillovers relative to the futures is related to whether it is the underlying asset of the futures.

The fifth column reveals a pattern that is different than the third column, in spite of the fact that the fifth column is also a spillover rank from futures. Here, F_SC gives more volatility to only three out of the eight spots (Dubai, Tapis and ESPO), which documents the fact that F_WTI contributes more volatility spillovers to more spots than does F_SC. This can be explained by the fact that WTI futures lead other futures and are a predictor of volatility. Table 2 tells us that the direction and intensity of the spillover effect both have a certain regional property. Specifically, the closer the crude oil spots production area is to China, the more obvious the spillover effect will be between that area and F_SC (whether it is a volatility spillover or mean spillover and whether it is a recipient or a transmitter). Further, the higher the degree of internationalization of a type of spot is, the stronger its relationship with F_WTI will be (compared to F_SC). What's more, the futures also have a spillovers effect connection with their corresponding underlying assets.

Table 2: Relative spillover effects.

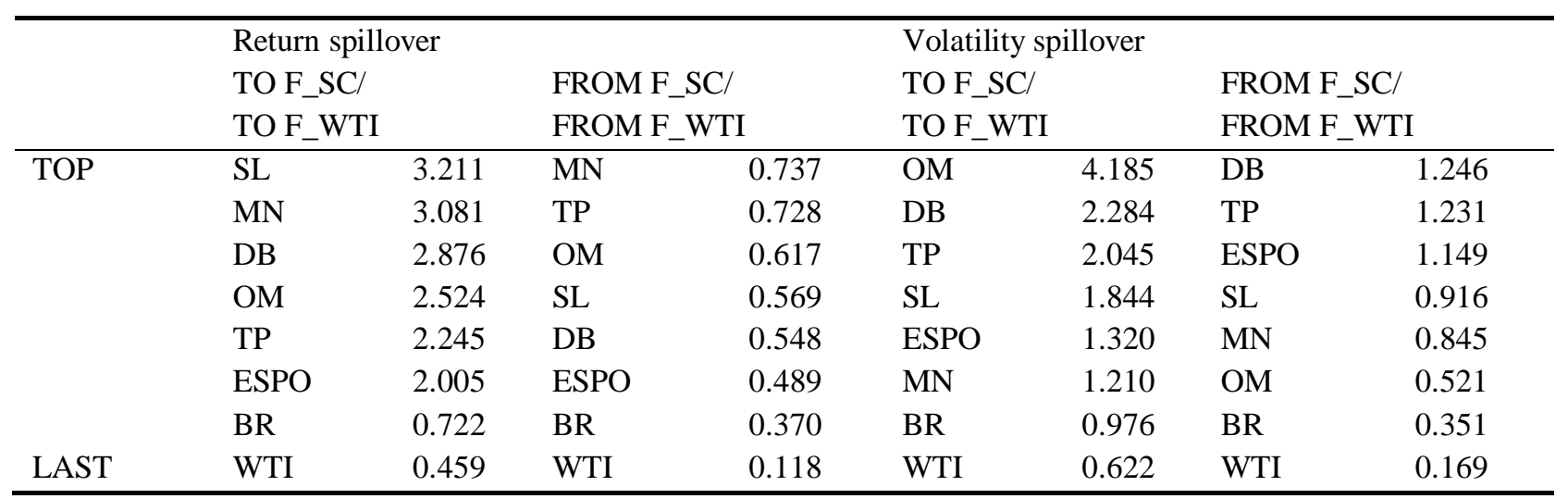


International Journal of Social Science and Economic Research

ISSN: $2455-8834$

Volume: 05, Issue: 03 "March 2020"

Table 3 shows the net spillover effects between spots and futures. The net mean spillover shows that the F_WTI is a net receiver only for Brent (2.1) and WTI (0.4). Table 3 also shows that WTI futures play a leading role in most of the spots we selected for this study. However, during the sample period, from March 2018 to March 2019, Brent and WTI had a net returns spillover effect on F_WTI. The F_SC was a pure receiver for all eight kinds of spots during the sample period, especially for Brent (6.4) and WTI (10.6). This is not surprising. As a new crude oil future issued in the financial markets of China, an emerging country, F_SC is vulnerable and likely to be influenced by the interference of spot crude oil price changes in surrounding countries or international markets. This finding can provide investors some inspiration.

The F_WTI is a net volatility spillover effects receiver only for WTI (0.36), while F_SC is the net volatility spillover effects transmitter only for Brent (8.8) and WTI (13.9), with relatively significant magnitude. Whether we look at F_WTI or F_SC, their volatility has caused spillovers to crude oil spots in Asia and Europe, especially in Southeast Asia. This shows that crude oil futures are a risk indicator. When futures fluctuate, the price risk of other products will also increase. We still find that WTI and Brent, as an important international crude oil spot, provide significant net volatility spillovers to F_SC.

Table 3: Net spillover effects.

\begin{tabular}{llllllllll}
\hline & & BR & WTI & SL & ESPO & OM & DB & TP & MN \\
Returns & F_WTI & 2.130 & 0.499 & -8.825 & -8.255 & -7.316 & -8.919 & -6.090 & -7.029 \\
Spillover & F_SC & 6.406 & 10.611 & 1.252 & 1.250 & 1.018 & 1.953 & 0.836 & 0.552 \\
\hline Volatility & F_WTI & -6.959 & 0.363 & -5.244 & -2.160 & -6.820 & -7.338 & -2.774 & -7.636 \\
Spillover & F_SC & 8.856 & 13.947 & -3.647 & -1.737 & -1.917 & -4.817 & -2.149 & -5.016 \\
\hline
\end{tabular}

Note: A value greater than 0 indicates that futures are a receiver, otherwise, transmitter.

\subsection{Dependence structure between crude oi futures and spots}

Using a Markov-switching model and dynamic parameter t-copula, we discover the regimeswitching dynamic dependence. In Figure 2, we put the dynamic correlation of the same spot and two different futures on the same raw, in order to compare the features between F_WTI and F_SC. What's more, in each sub-picture, we show the time span when State 2 occurs in a higher probability, using smooth probability in blue (futures) and grey (spots) shadows, in order to illustrate whether the state of change of an asset could affect the dynamic correlation between each pair. The DC of BR-F_WTI is positive during all time spans, while the DC of BR-F_SC is negative in mid-October. This finding vividly illustrates that the state of change of futures and spots may influence the dependence structure where, at each state of transition, the DC curve dips dramatically. Totally, the mean of the DC of BR-F_WTI is higher than that of the DC of BRF_SC. It seems strange that the DC of WTI-F_WTI is almost a straight line during the time span, 


\section{International Journal of Social Science and Economic Research}

ISSN: $2455-8834$

Volume: 05, Issue: 03 "March 2020"

which shows a static pattern in dynamic correlation. It is no surprise that the price movements of WTI and F_WTI maintain a highly consistent movement. However, the DC of WTI-F_SC stays at a relatively low level, and as the state of F_SC changes, the DC of WTI-F_SC also experiences a large rise and fall, thereby reflecting the impact of state changes on dynamic correlation. We can assume that the dynamic correlation between international crude oil spots (Brent and WTI) and F_WTI is much higher than their dynamic correlation with F_SC. Dynamic correlation is an important basis for hedging, so this information provides recommendations for those engaged in international crude oil hedging.

In this study, ESPO also exhibits a different feature of dynamic correlation with F_WTI and F_SC. The DC of ESPO-F_WTI goes ups suddenly as the state of F_WTI changes. What's more, the DC of ESPO-F_SC goes downs dramatically as the state of ESPO changes and goes up as the state of F_SC changes. These patterns cannot be ignored by investors.

The DC of DB-F_WTI experiences a negative time span in January 2019, and it changes dramatically when the states of DB and F_WTI change. However, contrary to this pattern, the DC of DB-F_SC remains at a very high level, which is also markedly higher than the DC of DCF_WTI. This happens even without dramatic changes, regardless of the state changes of DB and F_SC. Also, as an important crude oil in the Middle East, Oman oil spots showed similar characteristics to Dubai oil spots. This finding shows that the DC of OM-F_WTI (which is negative sometimes) is obviously lower than the DC of OM-F_SC. More precisely, the DC of OM-F_WTI and the DC of OM-F_SC seem not to have been influenced to any significant degree by the state changes of both spots and futures. The trajectory of the DC of OM-F_WTI swings up and down at 0.2. Both Middle East crude oil spots are more relevant to F_SC and less relevant to F_WTI. Investors can hedge against this characteristic.

Finally, we focus our attention on the crude oil spot market in China and Southeast Asia. Our findings show that the DC of SL-F_WTI changes when the state of SL changes. However, no patterns are seen, which suggests that the DC of SL-F_WTI will change vividly as the state of F_WTI changes. In the study period, the DC of SL-F_WTI remains above positive, which is different from the pairs we discuss above. However, the DC of SL- F_SC shows that it may change when the states of futures and spots change. Further, when the states of SL and F_SC are in State 2, the DC reverts to a high value. This reflects the importance of using the Markovswitching model. The statistical description shows that the average of the DC of SL-F_SC is much higher than the DC of SL-F_WTI. China's crude oil futures are indeed very suitable for investment or for hedging with China's crude oil spot portfolio. This was one of the original intentions of establishing China's crude oil futures, and through an empirical study, we find that this objective was achieved during the sample period. 
Crude oil in Southeast Asia also exhibits similar characteristics to Chinese crude oil. The DC of MN-F_WTI shows obvious changes when the states of spots and futures change. The situation is the same in the DC of MN-F_SC where, whether in futures or in spots, the DC will spike or plummet at the critical point of each state of transition. The DC of MN-F_SC reaches a low level in mid-2018 and reverts to a stable-high level in late-2018, at which they both experienced a price drop. The DC of MN-F_SC is markedly higher than that of MN-F_WTI. The trajectory of the DC of TP-F_WTI is similar to that of the DC of SL-F_WTI, which is no doubt caused by the same price trajectory between Shengli oil spots and Tapis oil spots. A numerical mutation occurred in the DC of TP-F_SC when the state change did not occur, especially on January 7 , 2019. This anomaly can be explained by the fact that the returns of F_SC are more volatile. The DC of TP-F_WTI and the DC of TP-F_SC are both positive, while the latter is higher than the former in terms of magnitude. This finding reveals the fact that the nexus between Tapis and F_SC is much closer to that of Tapis and F_WTI.

Overall, F_WTI is more closely linked to WTI and BR. Other spots show patterns of being more closely linked to F_SC, especially DB and SL. This is not surprising, because DB and SL are both the underlying assets of F_SC. However, in other regions, such as crude oil in Southeast Asia (Tapis and Minas), Russian crude oil (ESPO) has shown a higher level of dynamic correlation with F_SC. This discovery paved the way for our hedging research. 
International Journal of Social Science and Economic Research

ISSN: $2455-8834$

Volume: 05, Issue: 03 "March 2020"
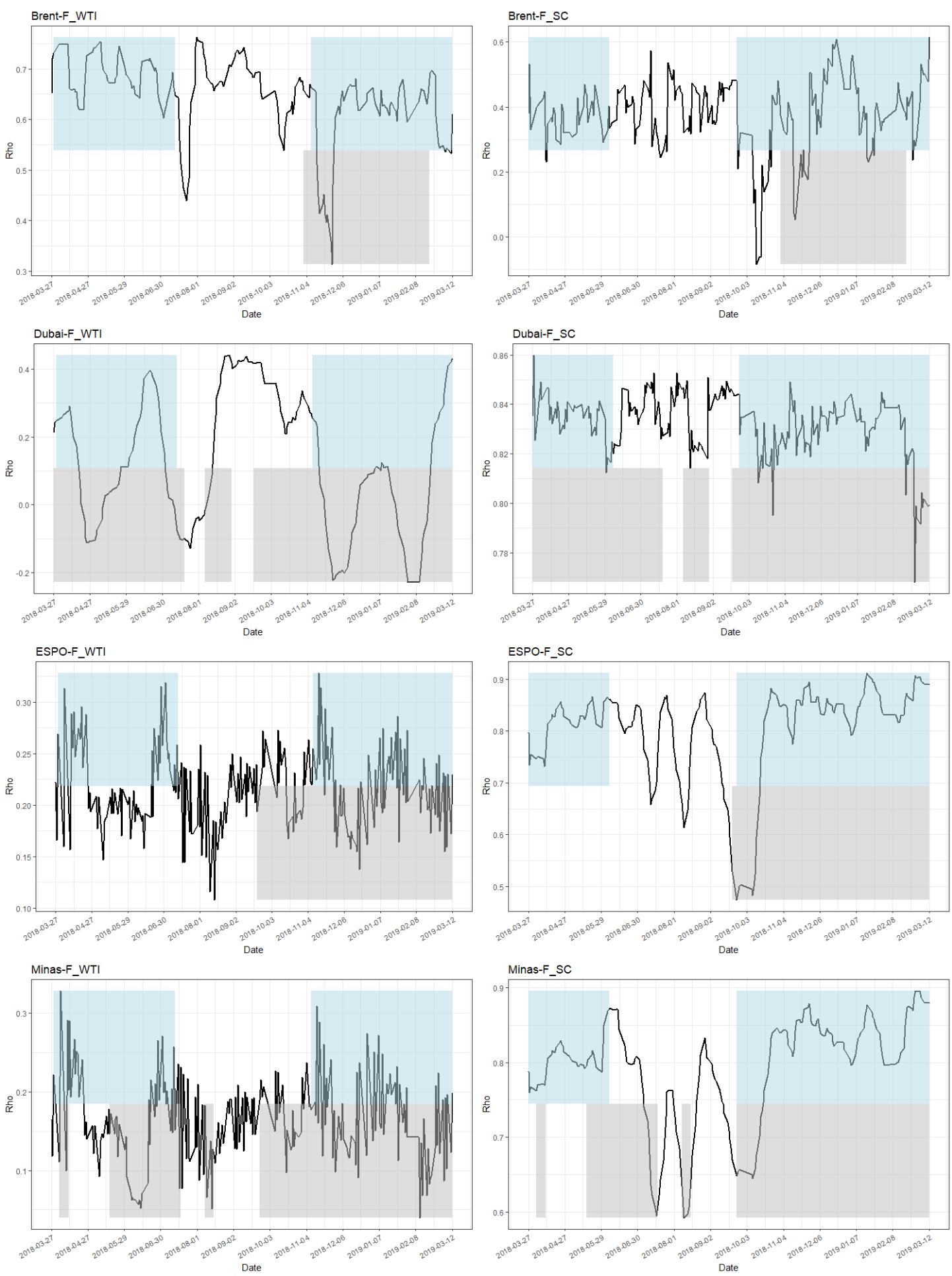

Fig. 2: Dynamic correlation between spots and futures 
International Journal of Social Science and Economic Research

ISSN: 2455-8834

Volume: 05, Issue: 03 "March 2020"
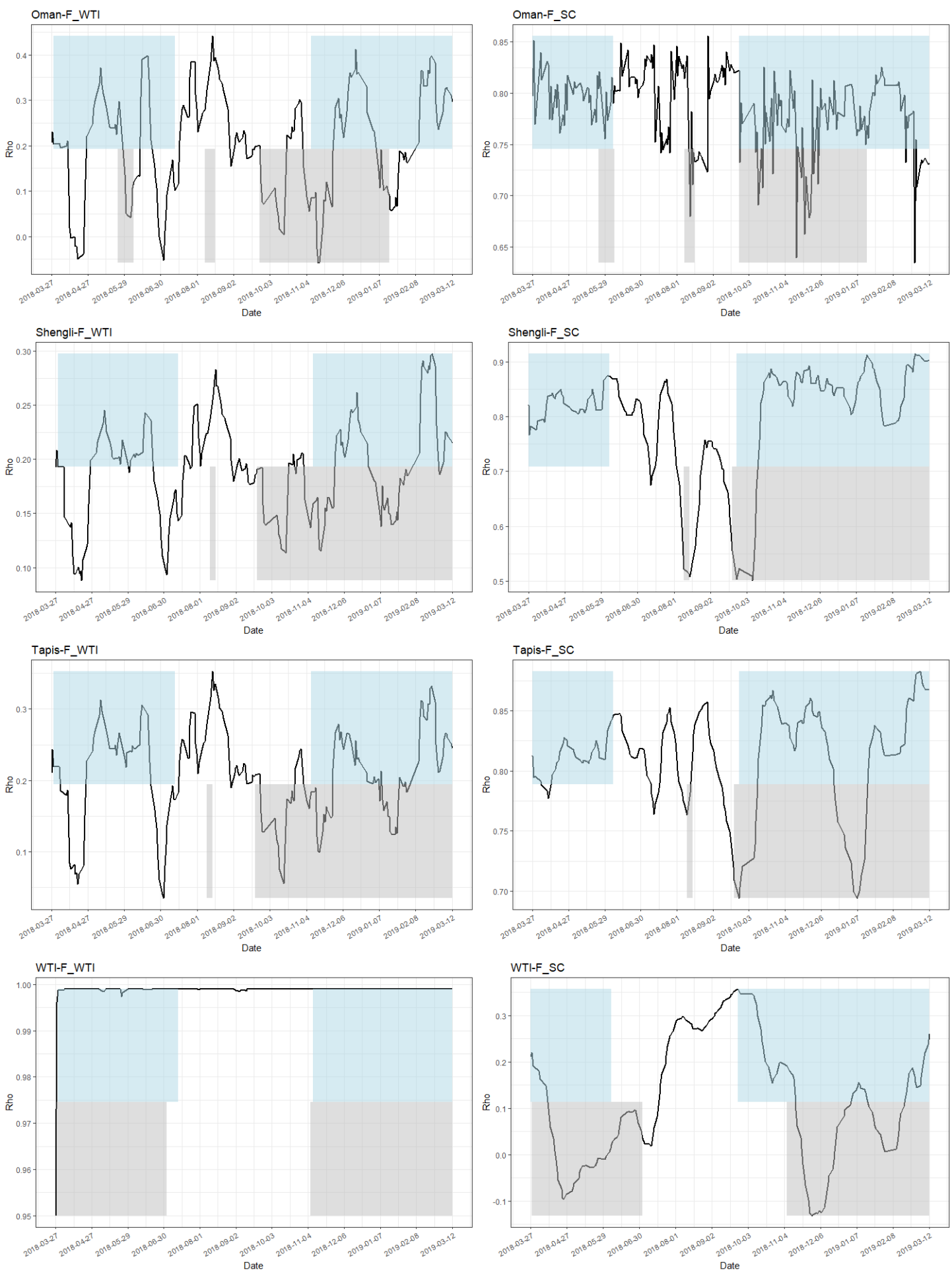

Fig. 3: Dynamic correlation between spots and futures (continue) 
International Journal of Social Science and Economic Research

ISSN: $2455-8834$

Volume: 05, Issue: 03 "March 2020"

\subsection{Performance of in-sample hedge at different hedge horizons}

Combining the dynamic correlation studies in the previous section, this section explores the hedging efficiency between different futures and stocks. Using the Markov-switching model to obtain conditional fluctuations and the dynamic correlation coefficients estimated by the tcopula, we can calculate the optimal hedging rate and hedging efficiency.

As shown in Table 4, with the exception of Brent and WTI, six out of the other eight spots had higher average hedging ratios. This finding indicates that F_SC is an expensive hedge tool, because the hedge ratio reveals how many units of contract of futures should be bought to hedge one unit of spots. Meanwhile, F_SC does not reflect hedge effectiveness. The S.D. shows that the S.D. of hedge ratios of a portfolio using F_SC is bigger in most pairs, compared to that using F_WTI. This finding indicates that investors should modify the numbers of hands of F_SC to a larger magnitude. This increases the difficulty of implementing hedging. A strange discovery is shown in Table 4, whereby the minimum value of some hedging rates is below 0 . This indicates that manufactories or hedgers should hold futures in a long position to offset one unit of spots in a long position. This conclusion can be explained by the fact that, in some periods, the returns of spots and futures may move in the opposite direction, and that situation cannot be found when using the static hedge strategy. The maximum of dynamic hedge ratio shows that, in some periods, the investors should take more than on unit of futures in a long position, in order to hedge the downside risk of spots. This finding illustrates the significance of futures price changes being less than spots price changes.

Table 4: Mean value of the time-varying in-sample hedge ratios at different time horizons

\begin{tabular}{llllllllll}
\hline & & BR & DB & ESPO & MN & OM & SL & TP & WTI \\
\hline Mean & & & & & & & & & \\
& F_WTI & 0.645 & 0.128 & 0.209 & 0.171 & 0.204 & 0.204 & 0.205 & 0.993 \\
S.D. & F_SC & 0.401 & 0.898 & 0.840 & 0.890 & 0.863 & 0.927 & 0.863 & 0.123 \\
& & & & & & & & & \\
& F_WTI & 0.092 & 0.200 & 0.044 & 0.059 & 0.123 & 0.053 & 0.072 & 0.016 \\
MIN & F_SC & 0.124 & 0.067 & 0.110 & 0.077 & 0.091 & 0.118 & 0.086 & 0.140 \\
& F_WTI & 0.291 & -0.240 & 0.104 & 0.039 & -0.055 & 0.099 & 0.034 & 0.948 \\
& F_SC & -0.092 & 0.703 & 0.454 & 0.642 & 0.493 & 0.528 & 0.663 & -0.155 \\
MAX & & & & & & & & & \\
& F_WTI & 0.787 & 0.482 & 0.326 & 0.364 & 0.532 & 0.376 & 0.431 & 1.032 \\
& F_SC & 0.698 & 1.064 & 1.043 & 1.086 & 1.156 & 1.117 & 1.073 & 0.371 \\
\hline
\end{tabular}

Note: S TO F (R) means that the return spillover effects go from spots to futures, while (V) means volatility spillover effect. 
Fig. 3 shows that, for most pairs (with the exception of Brent and WTI), the hedge ratios with F_SC are much bigger than with F_WTI in most time spans. This reveals the high cost of using F_SC for hedging. In the case of ESPO, Shengli, Tapis, and Minas, the hedge ratio with F_SC goes down sharply in mid-2018. The hedge ratio between WTI and F_WTI remains at 1, with little fluctuation, thereby reflecting that the co-movement between WTI and F_WTI is highly consistent. In addition, all hedging strategies show a very obvious dynamic feature.
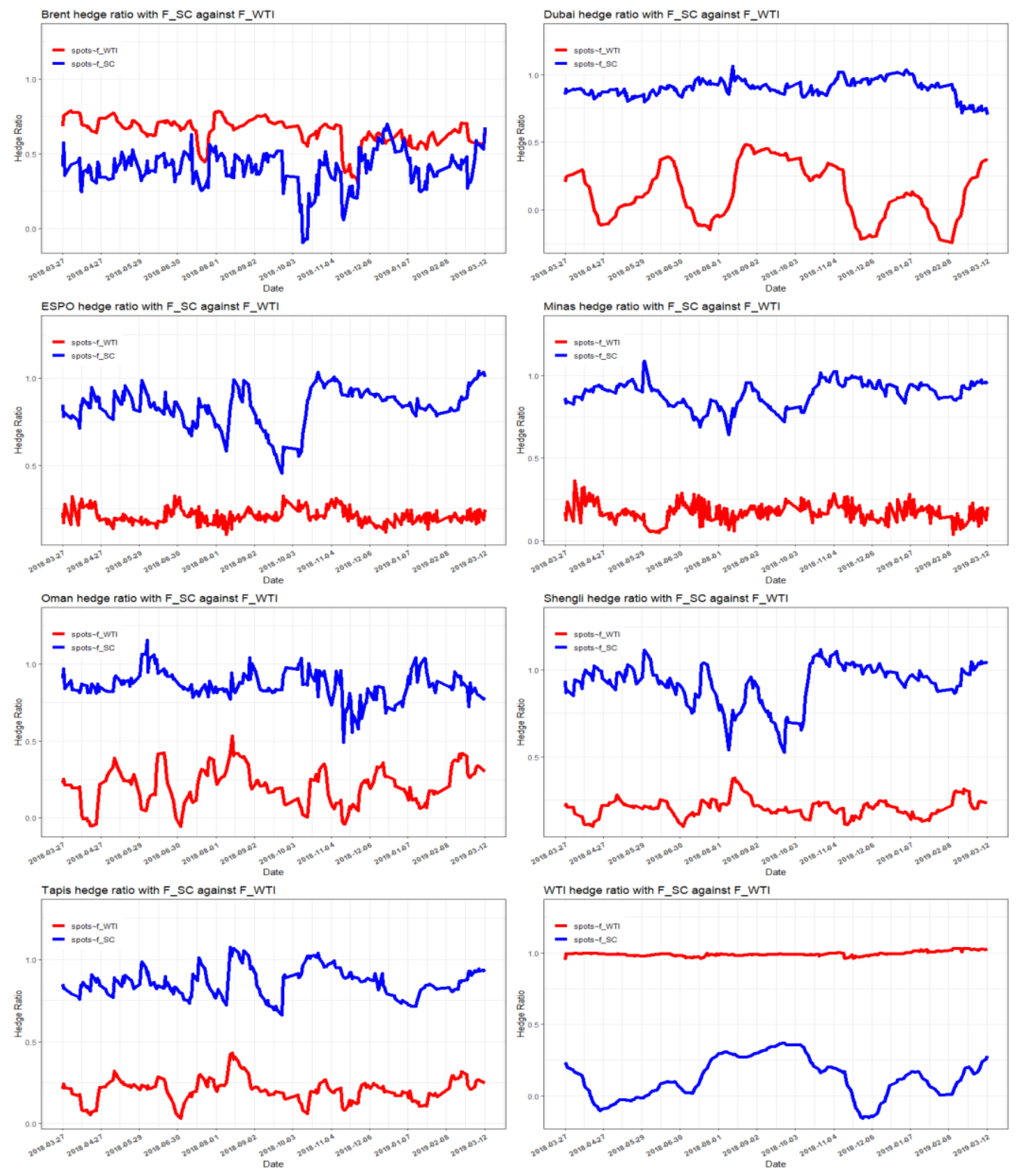

Fig. 4: Dynamic hedging ratio between spots and futures 
International Journal of Social Science and Economic Research

ISSN: $2455-8834$

Volume: 05, Issue: 03 "March 2020"

Table 5: In-sample static hedge at different time horizons

\begin{tabular}{llllllllll}
\hline & & BR & DB & ESPO & MN & OM & SL & TP & WTI \\
\hline 1 day horizon & & & & & & & & & \\
MS-GARCH-Copula & F.WTI & 0.444 & $\mathbf{0 . 0 8 3}$ & 0.045 & 0.027 & $\mathbf{0 . 0 5 9}$ & $\mathbf{0 . 0 3 5}$ & $\mathbf{0 . 0 4 6}$ & $\mathbf{0 . 9 6 7}$ \\
& F.SC & 0.131 & $\mathbf{0 . 6 9 8}$ & $\mathbf{0 . 6 2 9}$ & $\mathbf{0 . 6 0 9}$ & $\mathbf{0 . 6 1 1}$ & $\mathbf{0 . 6 4 7}$ & $\mathbf{0 . 5 9 7}$ & $\mathbf{0 . 0 5 9}$ \\
EGARCH-Copula & F.WTI & $\mathbf{0 . 4 4 5}$ & 0.029 & $\mathbf{0 . 0 7 2}$ & $\mathbf{0 . 0 5 2}$ & 0.045 & 0.026 & 0.033 & 0.952 \\
& F.SC & $\mathbf{0 . 1 4 8}$ & 0.675 & 0.607 & 0.607 & 0.580 & 0.639 & 0.591 & 0.054 \\
\hline 5 days horizon & & & & & & & & & \\
MS-GARCH-Copula & F.WTI & $\mathbf{0 . 6 7 1}$ & 0.137 & $\mathbf{0 . 3 2 2}$ & 0.211 & $\mathbf{0 . 2 1 1}$ & $\mathbf{0 . 2 3 5}$ & $\mathbf{0 . 2 5 4}$ & $\mathbf{0 . 9 9 3}$ \\
& F.SC & 0.431 & $\mathbf{0 . 8 8 2}$ & $\mathbf{0 . 8 2 6}$ & $\mathbf{0 . 7 2 8}$ & $\mathbf{0 . 8 0 9}$ & $\mathbf{0 . 8 5 3}$ & $\mathbf{0 . 8 3 1}$ & $\mathbf{0 . 1 2 5}$ \\
EGARCH-Copula & F.WTI & 0.635 & $\mathbf{0 . 1 9 7}$ & 0.143 & $\mathbf{0 . 2 2 9}$ & 0.169 & 0.187 & 0.212 & 0.974 \\
& F.SC & $\mathbf{0 . 5 0 4}$ & 0.855 & 0.806 & 0.694 & 0.802 & 0.845 & 0.817 & 0.105 \\
10 days horizon & & & & & & & & & \\
MS-GARCH-Copula & F.WTI & $\mathbf{0 . 7 0 6}$ & 0.100 & $\mathbf{0 . 3 4 9}$ & 0.230 & $\mathbf{0 . 2 3 0}$ & $\mathbf{0 . 2 6 0}$ & $\mathbf{0 . 2 9 0}$ & $\mathbf{0 . 9 9 7}$ \\
& F.SC & 0.443 & $\mathbf{0 . 9 1 1}$ & $\mathbf{0 . 8 6 4}$ & $\mathbf{0 . 7 2 1}$ & $\mathbf{0 . 8 5 9}$ & $\mathbf{0 . 8 8 5}$ & $\mathbf{0 . 8 8 4}$ & $\mathbf{0 . 1 0 5}$ \\
EGARCH-Copula & F.WTI & 0.685 & 0.209 & 0.079 & $\mathbf{0 . 2 4 4}$ & 0.187 & 0.206 & 0.242 & 0.977 \\
\hline 20 days horizon & F.SC & $\mathbf{0 . 5 5 0}$ & 0.877 & 0.830 & 0.685 & 0.850 & 0.870 & 0.861 & 0.066 \\
MS-GARCH-Copula & F.WTI & 0.703 & -0.047 & $\mathbf{0 . 3 3 6}$ & $\mathbf{0 . 2 2 0}$ & $\mathbf{0 . 2 6 3}$ & $\mathbf{0 . 2 8 2}$ & $\mathbf{0 . 3 2 5}$ & $\mathbf{0 . 9 9 8}$ \\
& F.SC & 0.483 & $\mathbf{0 . 9 2 5}$ & $\mathbf{0 . 9 0 8}$ & $\mathbf{0 . 7 2 9}$ & $\mathbf{0 . 8 7 0}$ & $\mathbf{0 . 8 9 4}$ & $\mathbf{0 . 9 0 9}$ & $\mathbf{0 . 0 2 2}$ \\
EGARCH-Copula & F.WTI & $\mathbf{0 . 7 1 6}$ & $\mathbf{0 . 2 1 5}$ & -0.019 & 0.194 & 0.207 & 0.212 & 0.241 & 0.976 \\
\hline 50 days horizon & F.SC & $\mathbf{0 . 6 3 3}$ & 0.898 & 0.859 & 0.701 & 0.865 & 0.881 & 0.86 & -0.046 \\
\hline MS-GARCH-Copula & F.WTI & $\mathbf{0 . 7 5 7}$ & 0.009 & $\mathbf{0 . 3 1 2}$ & $\mathbf{0 . 2 6 0}$ & $\mathbf{0 . 3 4 2}$ & $\mathbf{0 . 3 0 3}$ & $\mathbf{0 . 3 3 3}$ & $\mathbf{0 . 9 9 9}$ \\
\hline EGARCH-Copula & F.SC & 0.625 & $\mathbf{0 . 9 5 2}$ & $\mathbf{0 . 9 1 8}$ & $\mathbf{0 . 8 7 3}$ & $\mathbf{0 . 9 1 1}$ & $\mathbf{0 . 9 2 7}$ & $\mathbf{0 . 9 3 0}$ & 0.087 \\
\hline & F.WTI & 0.706 & $\mathbf{0 . 2 3 8}$ & 0.152 & 0.242 & 0.241 & 0.219 & 0.229 & 0.977 \\
\hline & F.SC & $\mathbf{0 . 7 4 1}$ & 0.925 & 0.870 & 0.870 & 0.892 & 0.925 & 0.892 & $\mathbf{0 . 0 8 9}$ \\
\hline
\end{tabular}

Note: S TO F (R) means that the return spillover effects from spots to futures, while (V) means volatility spillover effect.

However, the more expensive hedging price does not represent an inefficiency of hedging. What investors are more concerned about is whether the portfolio of hedged assets can reduce volatility (risk). In order to test the effect of hedging, we calculated the variance reduction ratio of the hedging portfolio during different holding periods. In addition, in order to determine the superiority of the MS-GARCH-copula model, we compared that model with the single EGARCH-copula model.

Table 5 summarizes the hedge effectiveness. In the table, the better futures, which hedge a specific kind of spots under a specific condition (model and horizon), are in bold. With the exception of some pairs, all pairs during different time horizons show that the VR of the MSGARCH-copula is bigger than that of the single EGARCH-copula. This is especially the case in Asia-Pacific spots, which shows that the Markov-switching model can vividly and adeptly 
International Journal of Social Science and Economic Research

ISSN: $2455-8834$

Volume: 05, Issue: 03 "March 2020"

expose the role of regime-switching in the volatility of spots and futures. Moreover, regimeswitching does exist and markedly influences the hedge ratio, thereby showing that the leverage effect does not exist at all times. Also, the EGARCH model can only reflect the average leverage effect over the sample period. However, a few pairs show that the EGARCH-copula has better hedge effectiveness. We think this is due to a certain degree of model misspecification (in this paper we only set the first order lag order) and the characteristics of the sample period. This, however, does not affect the superiority of the MSGARCH-copula model in describing the marginal distribution of spots and futures.

We turn to the in-sample hedging performance at the one-day horizon. With the exception of BR and WTI, the F_SC has an absolute edge against F_WTI. All the VR of six out of eight spots with F_SC are approximately 0.6 0.7, while, with F_WTI, the VR is only around zero. However, the VR of WTI-F_WTI at the one-day horizon is nearly 1 , and the hedge portfolio almost reduces $100 \%$ of the fluctuation of spots returns. The Brent hedging performance shows that the VR of BR-F_WTI is less than that of WTI-F_WTI, and the VR of BR-F_SC is very low, at around zero. This finding indicates that both F_WTI and F_SC are not perfect hedge tools for offsetting the rise and fall of Brent returns. This pattern seems to be related to their dynamic correlation coefficient and spillover effects. In addition to BR and WTI, the dynamic correlation coefficients of F_SC and the other six spots are significantly higher than that of F_WTI. The calculation of the hedging rate includes the dynamic correlation coefficient, which is the reason for the high hedging effect between the futures and the spots with high degrees of correlation. A notable finding is that the hedging effect between pairs with high relative spillover effects (regardless of direction) is also better. Combined with the findings in the previous sections, the spillover (whether returns or volatility) between F_SC and the spot in Asia is greater than the absolute value of F_WTI, or relatively larger. This has a similar correspondence to the hedging performance between each pairs.

With regard to the different time horizons, they all have similar patterns in hedging performance in the one-day horizon. A key finding here is that, with the time horizon lengthening, the hedging performance gets better. This provides investors with strong investment advice: if long-term hedges can be conducted, futures will be able to hedge against a large amount of spot volatility. This is because, in the long run, the pace of futures and spot linkage is consistent.

\section{CONCLUSION}

Since the initial issuance of China's crude oil futures, the volume of transactions has grown tremendously. China's entry into this market has largely affected the two major crude oil futures trading centers in NYMEX and IPE. This paper explores the linkage between Chinese crude oil futures and the world's major crude oil spot prices by comparing with China's futures with WTI 


\section{International Journal of Social Science and Economic Research}

Volume: 05, Issue: 03 "March 2020"

futures in four different aspects (returns spillovers, volatility spillovers, dynamic correlation and dynamic hedging ratios). The objective is to explore which futures have had a closer nexus with spots (Brent, WTI, ESPO, Dubai, Oman, Shengli, Tapis, and Minas) since the issuance of China crude oil futures.

Firstly, using the Diebold and Yilmaz (2012) spillover index, we find that WTI futures contribute more total returns spillovers and volatility spillovers for eight stocks than for China crude oil futures. This reflects the price leadership ability of WTI futures. From a global perspective, spillover information comes more from WTI futures than from China's crude oil futures. However, in terms of receiving total returns spillovers and volatility spillovers, China's crude oil futures receive more volatility spillovers and returns spillovers from the spots than from WTI futures. This finding shows that China's crude oil futures are the recipients of information. Investors in Chinese crude oil futures must consider the information of other financial markets, especially the Asia oil spots market.

Secondly, the dynamic parameter t-copula model reveals the dynamic correlation between futures and spot prices. In addition to WTI and Brent spots, the dynamic correlation of the other six spots and Chinese crude oil futures is significantly higher than WTI futures. There is a highly dynamic correlation between WTI spots and futures, while the dynamic correlation between Brent and WTI futures is relatively low.

Finally, the six spots, namely Shengli, Oman, Dubai, Tapis, Minas, and ESPO, have a variance reduction ratio of more than $60 \%$ with China's crude oil futures. The variance reduction ratio of the hedging portfolio between these six and WTI futures is very low, at less than $10 \%$. The portfolio of assets between WTI futures and WTI spots can cause the variance reduction rate to reach $100 \%$, while WTI spots and China crude oil futures can only reach approximately 5\%. In addition, WTI futures have a better hedge effect on Brent than do Chinese crude oil futures, but the hedging effect is very common. Almost all asset pairs show that the hedging efficiency calculated using the MS-GARCH model as the marginal distribution is better than the EGARCH model. In addition, as the length of the investment cycle increases, the hedging effect between all product pairs gets better and better.

Through the research in this article, we may provide inspiration to policy makers and market participants: Firstly, investors in China crude oil futures need to pay attention to other markets, especially the returns and volatility changes of crude oil spot markets in the Asia-Pacific region. Secondly, the linkage between China futures and Asia Pacific futures is good, maintaining a high degree of dynamic correlation. However, the dynamic correlation between the two spots of Brent and WTI is at a low level, so investors can use this feature to build a portfolio of assets for arbitrage or hedging purposes. Finally, China's crude oil futures are a very good hedging product 


\section{International Journal of Social Science and Economic Research}

ISSN: $2455-8834$

Volume: 05, Issue: 03 "March 2020"

compared to WTI futures. We also recommend that investors who use Chinese energy futures for hedging should make the hedging period longer, so that they can achieve a better hedging effect.

\section{REFERENCES}

[1] Ji, Q., \& Zhang, D. (2019). China's crude oil futures: Introduction and some stylized facts. Finance Research Letters, 28, 376-380.

[2] Huang, L., \& Li, J. (2018). Some Empirical Studies on Chinese Crude Oil Futures. Available at SSRN 3302485.

[3] Chi, K. M. L., \& Bilgin, M. H. (2013). Hedging with Chinese aluminum futures: international evidence with return and volatility spillover indices under structural breaks. Emerging Markets Finance \& Trade, 49(sup1), 37-48.

[4] Judge, A., \& Reancharoen, T. (2014). An empirical examination of the lead-lag relationship between spot and futures markets: evidence from Thailand. Pacific Basin Finance Journal, 29, 335-358.

[5] Brooks, C., Rew, A. G., \& Ritson, S. (2001). A trading strategy based on the lead-lag relationship between the spot index and futures contract for the FTSE 100. International Journal of Forecasting, 17(1), 31-44.

[6] Kang, S. H., Cheong, C., \& Yoon, S. M. (2013). Intraday volatility spillovers between spot and futures indices: Evidence from the Korean stock market. Physica A: Statistical Mechanics and its Applications, 392(8), 1795-1802.

[7] Diebold, F. X., \& Yilmaz, K. (2009). Measuring financial asset return and volatility spillovers, with application to global equity markets. The Economic Journal, 119(534), 158-171.

[8] Pesaran, M., H., \& Shin, Y. (1998). Generalised impulse response analysis in linear multivariate models. Economics Letters, 58(1), 17-29.

[9] Diebold, F. X., \& Yilmaz, K. (2012). Better to give than to receive: predictive directional measurement of volatility spillovers. International Journal of Forecasting, 28(1), 57-66.

[10] Hkiri, B., Hammoudeh, S., Aloui, C., \& Yarovaya, L. (2017). Are Islamic indexes a safe haven for investors? An analysis of total, directional and net volatility spillovers between conventional and Islamic indexes and importance of crisis periods. Pacific-Basin Finance Journal, 43, 124-150.

[11] Magkonis, G., \& Tsouknidis, D. A. (2017). Dynamic spillover effects across petroleum spot and futures volatilities, trading volume and open interest. International Review of Financial Analysis, 52, 104-118.

[12] Antonakakis, N., Floros, C., \& Kizys, R. (2016). Dynamic spillover effects in futures markets: UK and US evidence. International Review of Financial Analysis, 48, 406-418. 
[13] Yarovaya, L., Brzeszczyński, J., \& Lau, C. K. M. (2016). Intra-and inter-regional return and volatility spillovers across emerging and developed markets: Evidence from stock indices and stock index futures. International Review of Financial Analysis, 43, 96-114.

[14] Hou, Y., \& Li, S. (2013). Hedging performance of Chinese stock index futures: An empirical analysis using wavelet analysis and flexible bivariate GARCH approaches. Pacific-Basin Finance Journal, 24, 109-131. 